\title{
Notes on the Marchi method for staining degenerating myelin in the peripheral and central nervous system
}

\author{
SABINA J. STRICH \\ From the Department of Neuropathology, Institute of Psychiatry, London S.E.5
}

The Marchi method for staining degenerating myelin (Marchi, 1886) has exasperated and intrigued many because it is so useful yet prone to disturbing artefacts and because the reaction of osmium tetroxide with tissue components has interesting theoretical implications (Adams, 1965). Essentially, tissues are placed in a mixture of osmium tetroxide and an oxidizing agent such as $\mathrm{KClO}_{3}$; degenerating myelin then becomes black, whereas normal sheaths remain unstained. The method has been used mainly to demonstrate so-called Wallerian degeneration: when a nerve fibre is interrupted, the axon and myelin sheath of the piece severed from the cell body degenerate and the breakdown products of this process can be stained with Marchi fluid.

There are contradictory views about the chemical nature of the material which reduces osmium tetroxide in this procedure. Thus the material which stains with the Marchi method has been characterized as a lipid, probably cholesterol ester, by some (Adams, 1958; Wolfgram and Rose, 1958; Adams, 1960) and as a polysaccharide by others (Wolman, 1956, 1957). Conflicting opinions have also been expressed about the persistence of this material in the degenerating neural tissue. Some workers state that the method is only useful two to five weeks after the interruption of myelinated nerve fibres (Mettler and Hanada, 1942), whereas others have obtained satisfactory preparations from three days (Glees, 1948) to many months after the onset of the degeneration (Glees, 1943; Smith, 1956a). Similarly some authorities (Swank and Davenport, 1934; Mettler and Hanada, 1942; Glees, 1943) insist that the tissue to be stained should not be fixed for more than 48 hours, otherwise there may be loss of stainable material or increased artefacts; others claim good results, in some cases, years after fixation in formalin (Smith, 1956a; Smith, Strich, and Sharp, 1956).

In the course of an investigation of Wallerian degeneration it became clear that these apparent discrepancies are mainly due to failure to realize that differences in technique can affect the results $\mathbb{\Phi}$ of the Marchi method profoundly and that the material which can be stained with the Marchi ${ }^{\infty}$ method is not the same in acute and long-standing. degeneration. Furthermore, the process of Wallerian $\vec{\overrightarrow{ }}$ degeneration, particularly its time course, is different $\stackrel{\omega}{\sigma}$ in the peripheral and central nervous systems so that results obtained in the two situations are not directly comparable.

\section{MATERIALS AND METHODS}

The following observations on Wallerian degeneratio are based partly on human case material and partly @ experimentally produced Wallerian degeneration in the nervous system of the baboon.

HUMAN MATERIAL The brain and spinal cord of more $\vec{\theta}$ than 50 patients with destructive lesions in the nervoo system (trauma, leucotomy, cordotomy, cerebral in ${ }^{\circ}$ farction, etc.) were used, survival time varying from 48 hours to many years.

EXPERIMENTAL MATERIAL Wallerian degeneration was produced in 18 baboons by cutting peripheral nerves or $\frac{2}{\Phi}$ dorsal roots. The resulting degeneration in nerves, roots, $\varrho$ and in the dorsal columns of the spinal cord was studied $\overrightarrow{\vec{O}}$ after periods ranging from 27 hours to 428 days. The $\overline{3}$ findings in baboon and human material were similar.

There are many modifications of the Marchi solution mostly designed as an attempt to eliminate artefacts. In the present study the formula devised by Swank and Davenport (1935) was employed:

$1 \% \mathrm{KClO}_{3}-60 \mathrm{ml}$; $1 \% \mathrm{OsO}_{4}-20 \mathrm{ml}$; glacial acetic acid $-1 \mathrm{ml} . ; 37 \%$ formalin $-12 \mathrm{ml}$.

Two methods were used: (a) Block method. Slices of $\delta$ tissue $2-3 \mathrm{~mm}$ thick were put into the mixture for $10 \gtreqless$ to 21 days. Frozen sections were then cut off this block 의 or the block was embedded in paraffin wax or in celloidin before cutting sections. (b) Frozen section method. Frozen $\frac{7}{0}$ sections of formalin-fixed or of unfixed material were put into the Marchi fluid. After about eight days sections N were either mounted in glycerin jelly or dehydrated, cleared in xylene, and mounted in a synthetic resin such $N$ as XAM. 


\section{RESULTS}

For the present purpose the process of Wallerian degeneration can be divided into two stages.

STAGE I The Marchi reaction becomes positive some 72 hours after interruption of the nerve fibres. Degeneration shows as jet black, small or large irregular, angular, sometimes hollow, lumps when seen in cross section of degenerating tracts (Fig. 1a) and of irregular sausages, balls, or beaded strings in longitudinal sections. In the peripheral nervous system this type of Marchi material is present for 10 to 14 days but in the central nervous system it remains prominent for 10 weeks or so after the onset of degeneration and then gradually decreases in quantity. The material has the following characteristics: (a) It stains only if a block of tissue has been placed in the Marchi fluid (Fig. 2a). Frozen sections put into the mixture remain completely unstained (Fig. 2b), degenerating myelinated fibres are not blackened and there is little artefactual staining of normal myelin. (b) This Marchi positive material is not soluble in alcohol, xylene, or chloroform. Treated

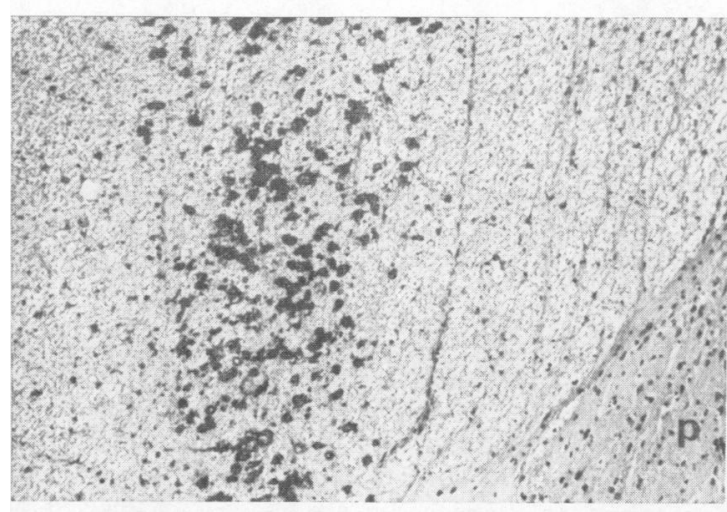

FIG. 1a.

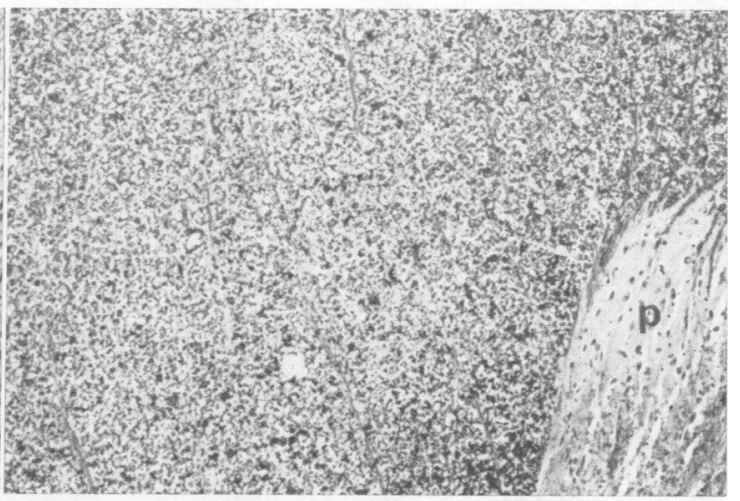

FIG. 1 b.

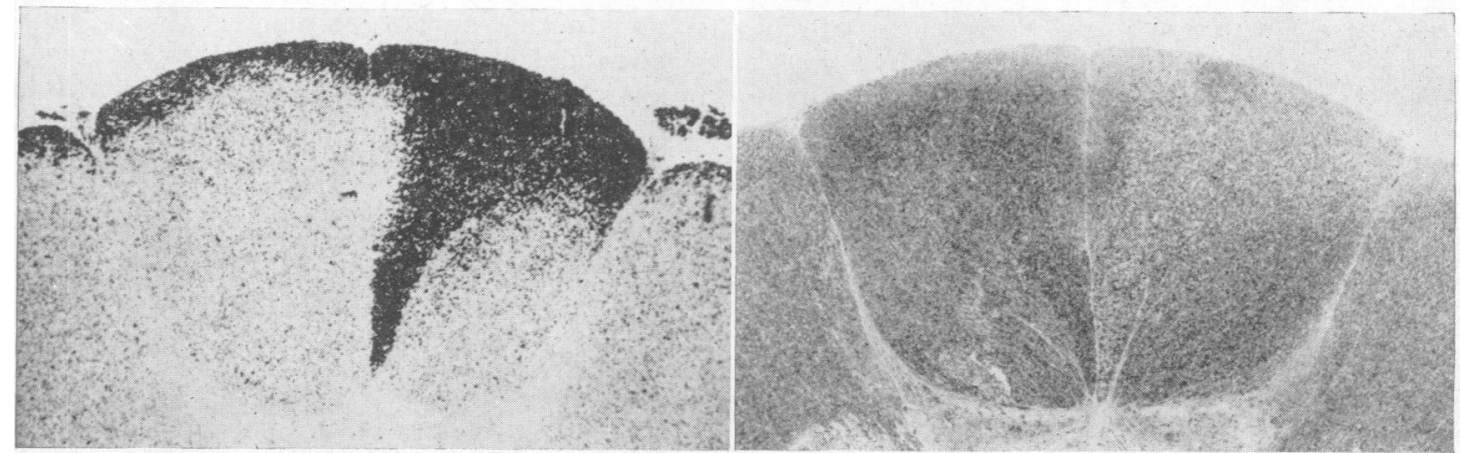

FIG. $2 \mathrm{a}$.

FIG. $2 b$.

FIG. 1. Transverse sections of dorsal column of the cervical spinal cord of a baboon four days after cutting lumbar dorsal roots. Frozen sections were cut from blocks of cord which had been stained by the Marchi method; sections were dehydrated, cleared, and mounted in synthetic resin (XAM).

(a) After 48 hours fixation in formalin. Black degeneration products are clearly seen.

(b) After six month' fixation in formalin. The degenerating tissues no longer stain. $p=$ posterior horn. $\times 110$.

FIG. 2. Transverse sections of cervical spinal cord of a baboon 52 days after cutting some lumbar dorsal roots on one side.

(a) $A$ block of cord was stained in Marchi fluid and embedded in paraffin wax. The section shows clearly defined tract degeneration in one dorsal column and pseudo-degeneration, most dense round the edge of the cord.

(b) Frozen section from an adjacent block of spinal cord. The section has been stained in the same Marchi fluid as the block in (a) but the degenerating tract has not blackened. There are no pseudo-Marchi deposits. $\times 22$. 
blocks can, therefore, be embedded in paraffin wax or in celloidin without loss of degeneration products. Frozen sections cut off an impregnated block are satisfactory. (c) The material completely disappears or becomes unstainable in the course of a few weeks of fixation of the tissue in formalin (Figs. 1a and b).

The Marchi positive material is densest in the degenerating tracts but it is usually also present in variable amounts in other regions, particularly around the edge of the block. In areas of such pseudodegeneration normal myelin sheaths appear as black rings in transverse sections or as long rods in longitudinal sections. In other areas the artefactual staining of nervous tissue presents as intensely black lumps of various sizes which are practically indistinguishable from the Marchi positive material in the degenerating tracts (but see Smith, 1956b). The amount of this pseudo-degeneration, also known as pseudo-Marchi or Marchi dust, is unpredictable and can make the interpretations of results difficult. It seems to be least obtrusive in frozen sections which have been cut from block impregnated material or in paraffin sections which have been counterstained with, for example, cresyl violet or Mallory's trichrome stain.

It is difficult to identify the material which becomes black in Marchi fluid, in adjacent sections stained with Oil-red-O, Sudan IV, Sudan black, or the periodic-acid Schiff method (frozen or paraffin sections). It does not stain with the Schultz reaction for cholesterol and cholesterol esters, nor can it be impregnated with silver salts in frozen or paraffin sections. In sections stained with osmium tetroxide alone or with Baker's acid hematein or with Luxol- fast-blue the degenerated areas can be recognized.ô The myelin sheaths are broken into short fragments $Z$ and, at first, are distended with what is probably swollen axoplasm; later the sheaths are collapsed andō appear solid. Throughout this time (many weeks in the central nervous system) the stage I March reaction is positive (Figs. 1a and 2a), but it is notes clear what substances or structures are actuallyô stained by this method. Nerve and tract degeneration are clearly seen using the block impregnation Marchi technique long before chemical changes in myelin lipids can be detected at $\mathbf{1 0}$ days in peripheral nervesen (Johnson, McNabb, and Rossiter, 1950) or at $100 \mathrm{~g}$ days in optic nerve, representing central nervous system myelin (McCaman and Robins, 1959).

STAGE II Later in the course of degeneration following interruption of myelinated nerve fibres a different ${ }_{-}^{\infty}$ type of Marchi positive material appears. It consists. of aggregates of brown or grey-black granules (Fig. $\vec{\omega}$ 3a) and of blackish crystals. Much of this materialo is red in sections stained with Oil-red-O and appears? to be contained in fat granule cells. Histochemicalo tests (Schultz reaction) indicate that most of this $\omega$ type of Marchi substance consists of cholesteryin esters.

This Marchi material has the following character? tics: (a) It stains irrespective of whether frozen sections or tissue slices are placed in the Mare⿻ fluid (Fig. 3a). (b) It is not soluble in alcohol bgto dissolves in chloroform or xylene (Fig. 3b). Frozen sections must be mounted in water-soluble mounti $\overrightarrow{\mathrm{g} g} \overrightarrow{\mathrm{Q}}$ medium and, in contrast to the early degeneratiơnco products, at the later stages of myelin breakdowno

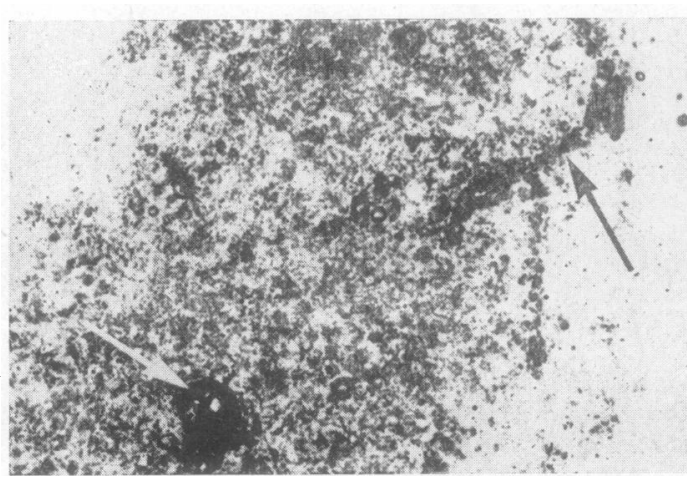

FIG. 3a.

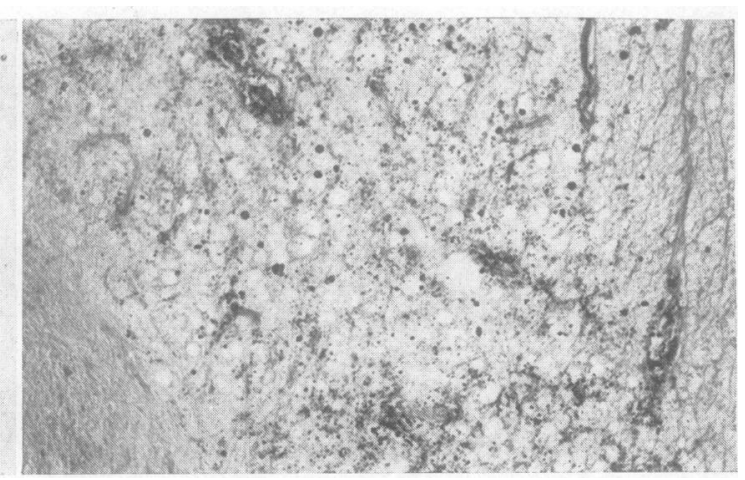

FIG. 3 b.

FIG. 3. (a) Frozen section of dorsal column of a baboon 224 days after cutting of dorsal roots. The section has been stained in Marchi fluid and mounted in glycerine jelly. Granules and aggregates of Marchi positive material are seen. There are perivascular accumulations of breakdown products (arrows). Compare with Fig. 2(b).

(b) Frozen section from the same spinal cord as in (a). The section has been stained in Marchi fluid, dehydrated, cleared in xylene and mounted in a synthetic resin $(X A M)$. Most of the Marchi-positive material has been dissolved. $N$ $\times 88$. 
some stained material will be lost during paraffin wax or celloidin embedding. One curious fact emerged: if frozen sections or blocks of tissue are left for some time in $70 \%$ or $80 \%$ alcohol after having been in Marchi fluid, the black material becomes insoluble in xylene and sections can be dehydrated, cleared, and mounted in XAM or balsam. Thus if blocks are dehydrated very slowly they can be embedded in paraffin wax or in celloidin without loss of Marchi positive material. (c) Late myelin breakdown products are unaffected by storage of tissues in formalin and will stain well for at least 15 years after fixation. (d) In the peripheral nerves late degeneration products appear some 10 to 14 days after nerve section. In the central nervous system, on the other hand, stage II Marchi material becomes demonstrable only 80-100 days after cutting the dorsal roots in baboons (between 80 and 200 days after onset of degeneration, both types of Marchi material can be seen in block impregnated tissues). In human material stage II Marchi substances are also best seen three to four months and longer after interruption of nerve fibres in the central nervous system and much is still present two years after the onset of degeneration. After months most of the material still lies in the degenerated tracts, but there is then a tendency for a perivascular accumulation of breakdown products (Fig. 3a). The results are summarized in the Table.

SOME PROPERTIES OF SUBSTANCES FORMED DURING WALLERIAN DEGENERATION AND STAINABLE WITH THE MARCHI METHOD

Degeneration products

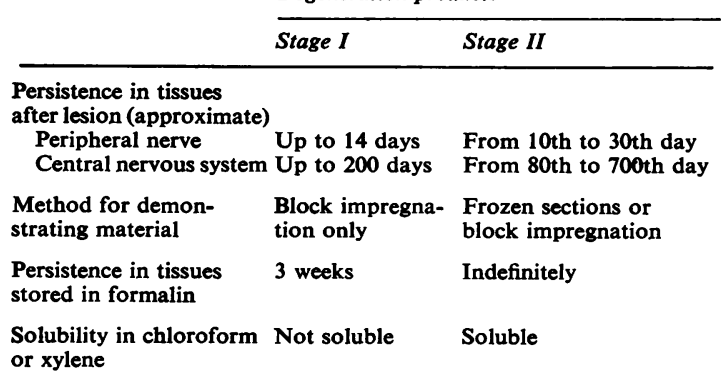

Probable chemical nature Not known Cholesterol esters

\section{DISCUSSION}

Some of the findings listed above have already been reported by others (Swank and Davenport, 1935; Smith, 1956a). Smith (1956a) showed, on human cordotomy material, that the Marchi positive substances in long standing, as opposed to acute degeneration, were unaffected by formalin and were contained in fat granule cells. In her cases the change from 'early' to 'late' Marchi material began about 80 days after the placement of the lesion.
There is good chemical and histochemical evidence that the stage II Marchi material consists of cholesterol esters both in the peripheral nervous system (Johnson et al., 1950; Adams, 1958) and in the central nervous system (Adams, 1960). The substances responsible for the reduction of osmium tetroxide in the first stage of Wallerian degeneration have not been adequately investigated. Wallerian degeneration in the central nervous system is evidently a much slower process than in the peripheral nervous system. Similar types of Marchi positive substances are, however, formed in both situations.

It is clear that differences in the technique of the Marchi method and differences in experimental design can affect the results profoundly and lead to apparently contradictory conclusions. Workers who, like Adams (1958, 1960, 1965), use the method with frozen sections, ipso facto never see or study early, stage I Marchi positive material and the same may be said of those who study myelin degeneration in the peripheral nervous system 14 days or longer after nerve section. The results of such investigations cannot, without qualification, be compared with those of Wolman $(1956,1957)$, for example, who was specifically interested in early Wallerian degeneration. It is hoped that the information presented here will be useful both to those who use the Marchi method for anatomical studies and to those interested in the chemistry of myelin and its breakdown products.

\section{SUMMARY}

The Marchi method stains breakdown products formed during Wallerian degeneration of myelinated nerve fibres. The substances which reduce osmium tetroxide in the early stages of this process are chemically and morphologically different from those which do so later on. Breakdown products formed during the early stages of Wallerian degeneration cannot be stained by immersing frozen sections in Marchi fluid (blocks of tissue must be used) nor can they be demonstrated in tissues which have been in formalin for some time. Wallerian degeneration is slower in the central nervous system than in the peripheral nervous system.

This work would have been impossible without the collaboration of Professor P. M. Daniel. I am grateful to Mrs. Edwina F. Barrett, F.I.M.L.T. for the technical work and to Mr. P. M. Taylor for the photographs. The work was supported by a grant from the National Fund for Research into Crippling Diseases.

\section{REEERENCES}

Adams, C. W. M. (1958). Histochemical mechanisms of the March reaction for degenerating myelin. J. Neurochem., 2, 178-186. (1960). Osmium tetroxide and the Marchi method: Reactions with polar and non-polar lipids, protein and polysaccharide. J. Histochem. Cytochem., 8, 262-267. 
Adams, C. W. M. (1965). Neurohistochemistry. pp. 36-39, 442. Elsevie Publishing Company: Amsterdam, London, and New York.

Glees, P. (1943). The Marchi reaction: its use on frozen sections and its time limit. Brain, 66, 229-232.

- (1948). The time factor in central nerve fibre degeneration Acta Anat. (Basel), 6, 447-450.

Johnson, A. C., McNabb, A. R., and Rossiter, R. J. (1950) Chemistry of Wallerian degeneration. A review of recent studies. Arch. Neurol. Psychiat. (Chic.), 64, 105-121.

McCaman, R. E., and Robins, E. (1959). Quantitative biochemica studies of Wallerian degeneration in the peripheral and central nervous systems. I. Chemical constituents. J. Neurochem., 5, 18-31.

Marchi, V. (1886). Sulle degenerazioni consecutive all' estirpazione totale e parziale del cervelletto. Riv. sper. Freniat., 12, 50-56.

Mettler, F. A., and Hanada, R. E. (1942). The Marchi method. Stain Technol., 17, 111-116.
Smith, M. C. (1956a). Observations on the extended use of the Marchi method. J. Neurol. Neurosurg. Psychiat., 19, 67-73. (1956b). The recognition and prevention of artefacts of the Marchi method. J. Neurol. Neurosurg. Psychiat., 19, 74-83.

- Strich, S. J., and Sharp, P. (1956). The value of the Marchi method for staining tissue stored in formalin for prolonged periods. J. Neurol. Neurosurg. Psychiat., 19, 62-64.

Swank, R. L., and Davenport, H. A. (1934). Marchi's staining method 2. Fixation. Stain Technol., 9, 129-135.

- (1935). Chlorate-osmic-formalin method for staining degenerating myelin. Stain Technol., 10, 87-90.

Wolfgram, F., and Rose, A. S. (1958). Chemical basis of the Marchi $\frac{\rho}{T}$ method for degenerating myelin. Neurology (Minneap.), 8, 839-841.

Wolman, M. (1956). Study of the early changes occurring in. degenerating myelin. Neurology (Minneap.), 6, 636-639. (1957). Histochemical study of changes occurring during the degeneration of myelin. J. Neurochem., 1, 370-376. 